ISSN: 1838-3815 (online) Journal Homepage: https://ojs.deakin.edu.au/index.php/itlge/

\title{
South African specific complexities in aligning graduate attributes to employability
}

\author{
Aradhana Ramnund-Mansingh ${ }^{1}$ and Nikita Reddy ${ }^{1}$ \\ Corresponding author: Aradhana Ramnund-Mansingh (Aradhana.mansingh@mancosa.co.za) \\ ${ }^{1}$ Mancosa Honoris United Universities, South Africa
}

\begin{abstract}
South African higher education (HE) cannot be compared to any other country's HE systems due to the unique political landscape and structural narrative that it has undergone. Subsequent to the reorganisation of HEls in 2004, a number of complexities arose. These included accessibility to education across race and the alignment of the South African HEls to global pedagogic benchmarks. With the changing political landscape, transformations within higher education, socio economic inequities and changes in the workplace, researchers failed to cognize the impact of these factors on graduate employability. Changing graduate attributes to align with a decolonised curriculum and Fourth Industrial Revolution (4IR) workspaces were transiently underway when COVID-19 set a new narrative for the future of employability. This paper seeks to identify the impact of workplace changes and its direct influence on successful graduate employment and integration into the HE curriculum. The work environment has cursorily moved from 4IR to an advanced stage of the 4IR, where there is a full emphasis on digitisation, non-localised workspaces and is an ostensible playground for digital natives (Generation Z). This paper provides a systematic review of literature in the South African HE contexts that pertains to graduate attributes for employability within the workplace. The adoption of malleable secondary data will allow for an understanding of the relationship between changing workplace environments and expectations from graduates. This correlation is directly linked to graduate attributes which students need to comply with from year one. The paper will provide context to changes which are required for the future success of graduates, and whether graduate attributes are adequate preparation for employability. A clinical model is recommended with an intervention to manage the risk factors of decolonisation of curriculum, the $4 \mathrm{R}$ and multi-generational workplace and responses to COVID-19.
\end{abstract}

\section{Introduction}

The South African 'landscape' is unique as attempts are made to rectify socio-economic inequities resultant from the historical separatist apartheid legislation. These historic inequities have had an impact on both the rising unemployment rates and the significantly high enrolment rate in higher education institutions (HEls). Although unsettled by the COVID-19 pandemic since March 2020, the South African HE sector has been in a state of turmoil since 2004. The year 2004 was a momentous year that marked the re-organisation of HE structures to make way for a system that is mutually 
inclusive to all races in a previously divided country. However, this structural re-organisation was met with challenges of institutional cultures, corporatised structures which eroded the tenets of academic freedom, a colonialised curriculum and an intention to benchmark against global HEls (Ramnund, 2019; Bentley, Habib, \& Morrow, 2006; Bitzer, 2009).

Amidst the institutional challenges, students suffered their own obstacles including the lack of finances to attend university, language barriers, and infrastructure obstacles exacerbated by geographic location and unaffordability to secure much needed resources. This became glaringly evident during the COVID-19 pandemic, when students were rendered vulnerable and had to return to their homes during the hard lockdown of level 5 in March 2020. Students who would rely on resources such as printing, computers, library and Wi-Fi at the HE campuses were left incapacitated. Numerous students live in geographic areas which had no data connectivity or infrastructure. Students could not afford expensive data bundles for online classes when the priority was for their families to survive amidst poverty and job loss (Maluleke, 2019; Seedat-Khan \& Ramnund-Mansingh, 2021; Sahu, 2020).

Current and prospective students began losing their motivation to obtain a tertiary qualification, being disillusioned at the alarmingly high unemployment rate, which is currently intensified by the COVID-19 pandemic. The General Household Survey (2019) indicated a school dropout rate of 230000 which has now trebled within COVID-19 to approximately 730000 (Macupe, 2021). Employability in itself is expansive in that workplaces are rapidly transforming to align with 4IR trends. Organisations are utilising advanced technological applications for their processes of recruitment and selection. HEls need to consider priming students for a competitive South African job market as well as making them employable globally. Taking these research gaps into consideration, this paper explores the current HE curriculum and graduate attributes in alignment with the current workplace. Deliberations in this discussion will respond to the historic inequities related to $\mathrm{HE}$ in South Africa, and current endeavours to decolonise the curriculum. These reflections are paralleled against the transforming workplace which has been affected by $4 \mathrm{IR}$ trends and a multi-generational workforce. Research questions that will be explored in order to address the purpose of the paper include understanding concepts of employability and graduate attributes, recognising the impact of decolonising of the curriculum and its relationship to employability, identifying workplace transformation resulting from $4 \mathrm{IR}$ trends and the expectations of graduates in a technological advanced 4IR and multi-generational workspace. These will be explored in a South African specific context.

\section{Literature review}

\section{Employability defined}

There is contention and variability with regard to definitions of employability, as it lacks a universally accepted definition. Scholars of diverse disciplines conceptualise varied definitions, and criticism for a precise and unambiguous definition is called for. For purposes of this paper, a detailed description by Mohee and Putty-Rogbeer (2020) is utilised,

Employability is not a static characteristic pertaining to an individual but rather a dynamic variable linked to the enhancement of skills, aptitude and knowledge within HEls and as required by the labour market and society in general. Drawing from the lifelong learning paradigm, employability is concerned with developing the ability in individuals for continuous learning within formal, informal or non-formal contexts. In this line, online and distance learning providers are considered as very influential in providing the necessary wherewithal for lifelong employability (p.1).

HE focuses on employability as a collective in understanding the supply, demand and conditions of the labour market. Li and Sun (2019), suggest that employability can be individualistic, and

Ramnund-Mansingh, A., \& Reddy, N. (2021). South African specific complexities in aligning graduate attributes to employability. Journal of Teaching and Learning for Graduate Employability, 12(2), 206-221. 
dependant on different global regions. Employability is referred to as career exploration or prediction and perception of individuals' external environment and job changes (Li \& Sun, 2019, p. 2).

Moreover, employability plays a significant role in the attributes of graduates in order to function effectively and be successful in a career (Onyeike \& Onyeagbako, 2014). Graduate attributes function beyond employability and have relevance to every aspect of the student's experience at a $\mathrm{HEI}$ which include linkages such as curriculum renewal, work related learning and personal development planning (McCabe, 2010). Employability can be considered as a two-pronged approach as it deals with the structural approach offered by HEls and a more individualistic approach of the perceived knowledge and skills required for the workplace.

A chronological analysis of research by Yorke and Knight (2006), Dacre Pool and Sewell (2007), Bridgstock (2009) and Hinchliffe and Jolly (2011) indicates the evolution of employability dimensions for HEls. Consistently similar with four dimensions, Dacre Pool and Sewell (2007), add on a fifth dimension of emotional intelligence. Drawing from these dimensions, Römgens, Scoupe and Beausaert (2020) developed a comprehensive structure of employability dimensions for HEls. This includes components of application of disciplinary knowledge, transferable generic skills, emotional regulation, career development skills, self-management and self-efficacy. This all-inclusive design is effective for the current employability platform, taking into consideration that economies and industries are in a constant state of flux. Mohee and Putty-Rogbeer (2020) have expanded this and identified seven transferable skills including creative problem-solving skills, teamwork, communication skills, soft skills, promotion of entrepreneurship, integrated career guidance and counselling and internationalisation. As an extension of their framework, Mohee and Putty-Rogbeer (2020) consider similar skills to that of Römgens et al. (2020).

Gupta and Garg (2020) maintain that HEls need to produce employable graduates by intellectual creativity development which is required for effective problem solving, Independent thinking, conflict resolution through negotiation skills and other $21^{\text {st }}$ century skills (p.4). The HEls responsibility in the development of student attributes is a constant thread throughout their strategic plan which includes learning, teaching and research. These attributes applied to different contexts shape students into graduates. Employability is not an outcome, but rather a process to be aligned with projects such as work integrated learning. Bennett et al. (2017) advocate for a pedagogical shift towards processual approaches in which responsibility for employability development is shared by academic and professional staff, students, and leadership (p. 59). This process and objectives of employability relies extensively on the alignment and partnership of key stakeholders including government and industry (Smith, Bell, Bennett, \& McAlpine, 2017).

\section{Graduate attributes}

Graduate attributes play a synergistic role in employability and prepare students for employment. The graduate attributes promoted by each university are often different due to the competitiveness of the higher education sector and the importance for universities to be different or distinctive from each other to attract students and build their brand (Wong, Chiu, Copsey-Blake, \& Nikolopoulou, 2021, p.2). Some of the common graduate attribute examples include creative and critical thinking; problem solving, teamwork and communication skill; professionalism and leadership readiness; and intercultural and ethical competency. Reports from industries in Australia and the United Kingdom confirm that while universities excel in imparting content related knowledge, the graduates lack practical business related skills such as communication (Jackson, 2012). Employers sought and prioritised graduates who possess practical competencies and 21st century skills such as problem solving and communication, with little to no mention of cultural understandings and attitudes towards inclusion and diversity (Oraison, Konjarski, \& Howe, 2019, p. 189). The expansion of businesses globally, multi-generational workspaces, attributes such as inclusivity and diversity should be a fundamental part of graduate attributes for employability.

Ramnund-Mansingh, A., \& Reddy, N. (2021). South African specific complexities in aligning graduate attributes to employability. Journal of Teaching and Learning for Graduate Employability, 12(2), 206-221. 
Studies (Gill, 2018; Ruge, Tokede, \& Tivendale, 2019) have found a high correlation between successful graduate attributes and collaborative consultations with professional bodies. Engagement with industry and professional bodies cement the design of consistent graduate attributes. Whilst curricula and graduate attributes are often developed with industry involvement that endeavours to address the gap between academic goals and industry needs (Gill, 2018), research findings suggest that these gaps continue to exist. There is an intense focus on graduate attributes at Australian HEls, where the outcome for graduates is to develop them to a stage of being professionally ready (Ruge et al., 2019). This definition is underpinned by reviewing the curriculum and amalgamating it with personal and professional attributes. Amidst all the research, due to the structural variables in South Africa, the recommended approach by Scott, McLean, and Golding (2019) would auger well as they recommend peer mentoring for the successful attainment of gradate attributes.

\section{Transforming employability through the higher education lens}

Competition in the labour market in South Africa is excessive due to the lack of jobs for skilled graduates. The unemployment crisis is currently a global one with the COVID-19 pandemic. The unpredictable economies have resulted in companies shrinking their workforce. According to Zakaria, Yussof, Ibrahim and Tibok (2020), the expansion and supply of global HE delivery as well as global economy has influenced on the hiring needs of the employer. The employer's decisions to hire graduates are based on the quality and abilities that the graduate possesses in addition to the tacit knowledge and skills. However, both HEls and students have become more aware and acknowledge the change in the employment patterns, and are determined to work towards incorporating employable attributes in the relevant qualification programmes (Zakaria et al., 2020).

Zakaria et al. (2020) posit that there are claims from various stakeholders, mainly employers who describe graduates from universities as individuals who do not completely acquire the relevant employable attributes that are deemed essential in the workplace. HEls conceptualise skills and qualities of graduates differently. There is common terminology used such as transferable skills, key skills, soft skills, generic attributes, employability skills, competency, core skills and understanding tacit knowledge. The idea and concept of graduate employability embrace a thorough but allinclusive view on the required quality of a graduate in a community (Zakaria et al., 2020).

There are two main aspects to consider for employability such as discipline-specific skills and transferrable skills. According to Wickramasinghe and Perera (2010) subject skills are key aspects of the graduate's career in terms of providing knowledge and skill. They also note that transferable skills are the competencies which the graduate can apply in various job structures and professions throughout their career (Zakaria et al., 2020).

Research (Wickramasinghe \& Perera, 2010; Zakaria et al., 2020; Wimalasiri, 2015) validates that in a demanding and competitive labour market, students are made aware of the reality and that the role of their chosen academic qualification is influential in their employment outcomes. This has been acknowledged as a value added to acquire employability attributes in order to gain a competitive advantage in the industry. Students now realise the importance of these attributes which are developed through the university curriculum, as well as qualities of personal growth.

A study by Morrison (2014) confirms the views of lecturers' that the expectation from employers from HEls is to provide graduates with specific employability and leadership skills. These attributes are critical thinking, ability to articulate and self-confidence. Additionally, the most common attributes graduates leave the university with are communication skills, information management, leadership, teamwork and ethics.

Wimalasiri (2015) asserts that specific roles in the workplace requires a blend of various transferable skills, self-management, business acumen, literacy and numeracy skills. Ahmadi and Helms (1997) rationalise that graduates have a tendency to start their working life in larger companies as the jobs offered are not only attractive but also capable of uplifting a person's social status. Studies by Lau

Ramnund-Mansingh, A., \& Reddy, N. (2021). South African specific complexities in aligning graduate attributes to employability. Journal of Teaching and Learning for Graduate Employability, 12(2), 206-221. 
and Pang (1995) on undergraduate perceptions in a university in Hong Kong highlighted five attributes that influenced their decisions on careers. These attributes are opportunity for professional development, promotions, attractive salary, matched career development plan and excellent training.

According to student perspectives on employers' selection criteria, they indicate computing skills, the ability to work in teams, fluency in English and graduates' personality type are some of the most common employability skills. Alumni, industry and professional associations play an important role in boosting the employability of graduates. However, there is very little interaction among HEls with alumni and industry. There is a constant need for collaboration between these parties to ensure curriculum is developed in a way that it can serve both the need of employer/industry partner and the need of the student in order to transform and acquire the adequate graduate attributes suitable for employment. There are opportunities for graduate recruitment programmes and virtual internships which are available for graduates who have access to platforms which advertise these. Very few organisations partner with HEls regarding these opportunities.

These collaborations have been further distressed by COVID-19 which has rapidly forced educational institutions to move towards an online mode of delivery due to social distancing and the lock down protocols (Ali, 2020). Buckenmeyer (2010) iterates that computer technology provides the opportunities that were not available prior to the third industrial revolution, to enhance teaching and learning through simulations of complicated and time consuming scenarios. The current challenges for HE sector is on how to produce graduates as forward thinkers with creative ideas and relevant skills to operate in a digital space whilst still contributing to the organisations productivity. According to Oke and Fernandes (2020), the debate needs to realign from computer technology and focus on the transformation of the teaching and learning process inclusive of digitalisation by embracing 4IR. This shift will benefit the educational sector from the technology revolution and provide opportunity to address the predicament regarding the roles and effectiveness of digital technology in teaching and learning (Oke \& Fernandes, 2020).

\section{Employability within a 4IR context}

Penprase (2018) advances that as a result of the previous industrial revolutions, industrialisation has been firmly entrenched within the global economy. The third industrial revolution introduced machinery in the form of computers. This revolutionised work and communication, by channelling information expediently. 4IR underpinned by the use of digital technology goes beyond computers and e-materials. This is therefore compatible with a learner centred approach for the effective enhancement of student's experience in the learning journey. According to Oke and Fernandes (2020), 4IR, which is perceived as a fusion of many technologies and perceived to blur the boundaries between the physical, digital, and biological spheres, is now attracting increasing attention from policymakers, business practitioners, and academics ( $p$.31). Technology innovations, including the application of smart devices with various uses including social media may reduce face to face social interaction substantially. This could affect the acquisition of relevant required skills with the limitation of developing soft skills such as emotional intelligence, interpersonal skills and communication amongst youth (Oke \& Fernandes, 2020).

While many global entities including business and HEls have embraced many facets of the digital evolution component of $4 \mathrm{IR}$, countries in the global south including South Africa lag severely behind. This is due to a number of factors. Although HEls in South Africa transformed in accordance to the HE Act 101 of 1997, curriculum used during the apartheid structures were still in use post transformation (Bitzer, 2009). Noting the global need to digitally transform, the Council for Higher Education in South Africa undertook firm decisions to prioritise the requirements. It served no purpose to digitise a colonialized curriculum with the inclusive and transformed HEls. Thus, decolonisation of the curriculum took precedence over digitisation. Additionally, South Africa like other countries in the global south continue to grapple with infrastructure for digital technology,

Ramnund-Mansingh, A., \& Reddy, N. (2021). South African specific complexities in aligning graduate attributes to employability. Journal of Teaching and Learning for Graduate Employability, 12(2), 206-221. 
especially within rural geographic areas, which are generously populated (Seedat-Khan \& RamnundMansingh, 2021).

Mohd Abas, Yahaya and Din (2019) suggest that the advancement in technology such as artificial intelligence (AI), robotics, and biotechnology will cause disruption to business models and labour markets over the next five years. The highly dynamic and competitive working environment of the twenty-first century demands a more innovative and flexible approach. An important distinction in current workplace practices is the reliance on applied technology and digital communities. Digital technology provides people with the benefit of interaction and communication with family and friends despite their work and study constraints. The concept of digital literacy refers to as a set of competencies required for inclusion in a knowledge society. This comprises of knowledge, skills and behaviours concerning the effective use of digital devices such as smartphones, tablets, laptops and desktop for collaboration, communication, and advocacy. Hence indicating the focal shift from desktops to data attached devices which is inclusive of social media (Mohd Abas et al., 2019).

The COVID-19 pandemic has highlighted the severe lack of digital infrastructure within South Africa. This is being addressed as the African Union (AU) has in place a comprehensive 50-year master plan which focuses on smart city infrastructure aligning to digital transformation and is fundamental for 4IR progression (Ramlachan, Ramnund-Mansingh, \& Naidoo, 2021). While countries in the global north were well prepared for online teaching and learning as COVID-19 lockdown protocol were initiated, the resource scarcity and digital infrastructure inadequacy has lamed countries such as South Africa during these pandemic times. The impact on business and HE will have far reaching implications for years to come.

\section{A multi-generational workforce}

A multitude of challenges plague graduates, including a dynamic 4IR workplace. The current workforce is a fluctuating space with multiple generations working together. This is significant for a number of reasons, the most noteworthy is their varying work ethic. From baby boomers to the workplace newbies which are Generation $Z$ or digital natives and everyone in between, share different traits including the generational upbringing to the work ethic and the manner in which they adapt and utilise technology.

There has been a substantial shift in priorities. Earlier workplace generations such as baby boomers and Generation X focused on job security, structured work days, and face to face interactions (Ozaydin, 2019; Lewis \& Wescott, 2017). This has been completed transmuted by the Generation $Y$ and Z. They thrive on finding the job that best suits them even if they move jobs every few years. They search for flexibility and ideally are able to choose the organisation they would like to work at in terms of their personal value alignment with the organisational culture. Generation $Z$ are determined to be highly connected, living in an era of high-tech communication, technology driven lifestyles and prolific use of social media (Gaidhani, Arora, \& Sharma, 2019, p.2806). Technology forms a large part of their identity. Generation $Z$ are entrepreneurial, entitled and materialistic. In the workplace, they prefer flexibility, personal freedom and environment that nurtures development (Schawbel, 2014; Bascha, 2011; Generational White Paper, 2011).

Due to the substantial focus on flexibility and personal freedom, the GIG mode of employment appeals to Generation Z. The GIG economy has become a significant part of the current workspace. No formal academic definition of the GIG economy is available (De Stefano, 2015; Abraham, Haltiwanger, Sandusky, \& Spletzer, 2019), although a working definition is the fundamentally changing the nature of work, with marked declines in full time and regular employment, more jobs classified as self-employed, more micro-business owner, contingent work, working as freelancers (however defined) or holding more than one job (Brinkley, 2016, p. 6). GIG employees undertake this paid work structures, voluntarily. The benefits to them is the flexibility of time and the ability for them to gain a multitude of skill sets. Global changes will keep the GIG economy relevant but with varying complexities. Being in a technological space, means that one job is accessible to millions of Ramnund-Mansingh, A., \& Reddy, N. (2021). South African specific complexities in aligning graduate attributes to employability. Journal of Teaching and Learning for Graduate Employability, 12(2), 206-221. 
individuals throughout the world which effects the supply demand principles and the market value thereof (Green, 2018). The positive implications for the younger Generation Z (also known as digital natives) is that they have opportunities to explore a diverse set of skills and experiences, globally (Donovan, Bradley, \& Shimabukuru, 2016). The contention with regard to GIG employees are their general employees' rights, the right to organise and the right to bargain. These employees are seen as independent contractors and fall outside of the ambit of labour legislation.

The 4IR has introduced technological innovations which are contributing towards extraordinary consequences on humanity and society, including business operation processes. Moreover, social media platforms, including Facebook, Instagram, Twitter and Linkedln have altered the fundamental building blocks of the way in which we interact with each other. Linkedln Learning and other Massive Open Online Courses (MOOC) platforms are transforming the way professional information, including teaching and learning, are disseminated. These platforms have considerable implications for HE and employability. With the Generation Z fixation on social media, it allows for employability and individual marketing via career and professional platforms such as LinkedIn. MOOC online platforms, such as Linkedln Learning and providers such as UDEMY allow individuals to upskill themselves on varied skills that stimulate them. These learnings align with their profile for GIG employment.

\section{Methodology}

This article provides a systematic review of literature in the South African and global HE context that pertains to graduate attributes for employability within the workplace. Secondary desktop resources proved useful. Due to the vulnerability and uncertainties of the COVID-19 global pandemic, this method is both cost-effective and safe. The purpose of primary research generally should be to fill in gaps in existing knowledge. These gaps cannot be identified without an understanding of the existing knowledge base. The term does not imply anything about the importance of the information, only that it is being used for research beyond the specific informational need that prompted the original gathering of the data. All primary research may ultimately become someone else's secondary source (Stewart \& Kamins, 1994, p. 4). Data sources were accessed through Google Scholar, SCOPUS and EBSCO.

\section{Information sources and search strategy}

An extensive literature search was conducted in August 2020. The search included scientific academic articles from both South African and global sources. Based on the authors' reflective experience in academia and industry practice, a need was recognised. South African specific challenges needed to be understood through a global lens.

\section{Eligibility criteria}

Globally, HE and the 4IR trends within the workplace should align, in theory. South Africa has unique challenges created by the political history and socio-economic inequity which continues to exist. Matters of a decolonised curriculum and attempts to enter a workforce within a country of $30 \%$ unemployment, as well as industries continuing to grapple with varying 4IR technologies and trends, were at the forefront of the study. Therefore, in considering the eligibility criteria, themes and key words surrounding the key concepts were highlighted. These themes provide context to these specific tribulations. There is disconnect between the curriculum design and the workplace success. Therefore, criteria used for developing the clinical model was dissected to understand the framework of graduate attributes, employability and the $4 I R$ perspective including a multigenerational workforce, which plays a significant role in employability success. Subsequent to examining the global agenda against the South African back drop, the clinical model was designed to mitigate the risk factors impacting on employability and the preparation thereof. At this stage

Ramnund-Mansingh, A., \& Reddy, N. (2021). South African specific complexities in aligning graduate attributes to employability. Journal of Teaching and Learning for Graduate Employability, 12(2), 206-221. 
amidst the changes brought about by the global pandemic, research will be remiss not to include COVID-19 as an identified risk.

\section{Study selection process}

The screening of titles and abstracts was conducted by one researcher (AM) to maintain consistency. The literature review themes were split and independently reviewed by both researchers. Several discussions took place among the researchers to present reviews to each other. Articles were deselected based on a lack of suitability which were in most cases a country specific incongruity which was not consistent with the study at hand.

\section{Data extraction}

This paper followed an interpretivist research paradigm with a qualitative approach and analysis of data. Data extraction focused on a comprehensive literature framework and outcomes related to graduate employability, attributes and the COVID-19 pandemic. Both researchers independently extracted data addressing criteria of these specific themes and how they would contribute to a clinical solution. Researchers added their comments to the table, any discrepancies were resolved via email or an online Zoom meeting. An in depth reading of data was explored followed by abstracting and identification of themes to form basis of the clinical intervention table.

\section{Theoretical underpinning}

The paper is underpinned by connectivism which is a learning theory based on the principle that knowledge starts with a connection. The process of obtaining knowledge begins with the individual who makes connections between entities (nodes) (Goldie, 2016). These nodes consist of individuals, groups, systems, fields, ideas or communities and can be accessed via internet technologies such as electronic databases, web search engines and online information resources, or through personal learning networks and socialization into the disciplinary context. The network of connections is expanded and continues the cycle of knowledge growth. The two aspects of connectivism in which learning occurs are the ways students interact in and between network nodes, and how they make connections between learning and the spaces in which they find themselves (Long \& Fynn, 2018).

Long and Fynn (2018) posit that there are four key terms including operation interaction, wayfinding, sense-making and innovation interaction. These concepts describe the distinct but interlinked processes that underpin learning in professional programs which require learners to develop a contextual sense of the theory and application of skills derived from the theories of the discipline. This interaction aligns graduate attributes to employability. Since each node that a student experiences throughout their journey in a higher education institution forms part of the student's developmental process; and alignment with each of the nodes contributes towards the employability of the graduate. The link between theory and application discerns both challenges and opportunities. This link requires an extension of the conceptualisation of how, when and where students learn. Therefore, HEls require further engagement from facilitation of students, curriculum in various faculty, and the practice to meet the demands of a dynamic marketplace (Long \& Fynn, 2018).

\section{Discussion and recommendations}

Scholarship on employability is exhaustive, as is the alignment of graduate attributes. The research gap lies in the South African specific context and literature. After review of significant studies in the subject matter, a clinical intervention model is recommended. There are three identified risk areas which are explored. These include decolonisation of the curriculum, advancing 4IR specific skills and response to crisis such as COVID-19 pandemic.

Ramnund-Mansingh, A., \& Reddy, N. (2021). South African specific complexities in aligning graduate attributes to employability. Journal of Teaching and Learning for Graduate Employability, 12(2), 206-221. 


\section{Decolonisation of the curriculum}

There is a need for curriculum reform towards decolonisation or Africanisation within South Africa's HEls (Mendy \& Madiope, 2020). The current curriculum is aligned with discriminatory frameworks which entrench past and current prejudices of material inequalities (Jansen, 1998; Heleta, 2016). These skewed systems of education will impact on the manner in which graduate attributes are translated. This will prove problematic for future graduates who enter a workplace with jaded lens as no congruency will exist between the HE curriculum and the workplace.

Decolonisation is particularly important within a South African context as education has been deeply rooted in structural inequities which endorse the colonised historical perspective. The educational system the country inherited from its colonial legacy has been thought not to be responsive to the needs of the country and its students' teaching and learning experiences (Mendy \& Madiope, 2020, p.7). The reformed decolonised curriculum will reflect the current realities of South Africa, indicative of the economic, political and social constraints.

The South African workplaces seek graduates who are able to immerse themselves in South African specific issues. Conflict related matters of race, mutual inclusivity and varying cultural expectations dominate the South African workplace. Specific cultural and linguistic colloquialisms and social norms play a significant part in the workplace. International organisations seek South African graduates for key personality attributes that emanate from an arduous history such as that of resilience and diplomacy. This is gleaned from separate research by Unger (2013), who similarly identifies that positive traits such as resilience can be developed from negative circumstances. These include the impact of nurture, environment and cultural variation. These are all factors which can be underpinned by a decolonised and holistic education system.

\section{A 4IR workplace}

Lewis (2020) advances that the concept of 4IR transforms the way we work and live. The introduction of various technologies and machinery such as robotics, genetic modifications, driverless vehicles, artificial intelligence (AI), the Internet of Things (IOT), nanotechnology, 3-D printing, and biotechnology; are transforming our behaviours, relationships, and causing us to question the meaning of humanity. Computers are now capable of inspecting and counting inventory faster and more efficient than humans can. 3D printers are capable of constructing a house in less than 24 hours. Robotic arms can now replace lost limbs. Advances such as these make it clear how $41 R$ will impact the way we work and how we work (Lewis, 2020, p. 349). The most discernible attribute of the $4 I R$ is the technological component of artificial intelligence, robotics and the internet of things. These are some of the critical skills set for employability. Higher education should play a considerable role in this. In South Africa the education disparities remain startling. Private schooling curriculums have incorporated the aspects of 4IR into their curriculum, but the almost 23000 public schools are left wanting. President Ramaphosa announced early in 2020 that 200 public schools will introduce coding and robotics into the foundation phase curriculum (Lindeque, 2020). This has been halted by the COVID-19 pandemic, but only constitutes less than $1 \%$ of the schools. The disparity lies in the fact that if higher education introduces these technologies as graduate attributes translated into employability skills, it will severely disadvantage the majority of students from public schools who do not have a basic understanding of these concepts and application. Aspects of coding, robotics and artificial Intelligence (AI) are integral 4IR workplace skills irrespective of the roles graduates are to fulfil. The human resources fraternity, for example, are embarking recruitment and selection techniques such as gamification interviews and assessments. The workplace is becoming a technological hub and graduates without these advanced skills are not only disadvantaged from the South African job market but the global job market as well.

Born and Drori, (2015) contend that both the workforce and the way work gets done are dramatically changing. Business operations are reshaping with the assistance of new collaborative 
and social technologies. The inflow of the generation $Y$ and $Z$ employees into the workforce is creating a new dynamic. This requires a unique organizational response in terms of the skill set required.

There are two key components within a 4IR workplace. These include a diverse workforce made up currently, of four different generations, and a technological way of adopting operational practices. The current dynamic has changed since Generation Z are now introduced in the workplace. Society delegates these generational personalities and characteristics into stereotypes, which align with the environmental influences that affect their beliefs, values, personalities, and expectations (Jones, 2017, p. 22). Studies conducted by Constanza at al. (2012) on preferences of different generations provide substantial insight to the demands and expectations and best mechanisms to recruit and retain the different generations. Although these studies are generic, it is adequate to inform a South African workforce.

The challenge of a multigenerational workforces is aggravated in South Africa by issues such as a lack of tolerance towards race, culture and gender which have been long entrenched by historic apartheid legislation. Accordingly, while global workplaces contend with multi-generations, equitable solutions for GIG employees and organisational learning cultures, South Africa's complexities vary as much of it is guided by retribution seeking legislation to equalise and balance workplace diversity. Compliance with legislation such as the BBBEE Act 53 of 2003, the Employment Equity Act 55 of 1998 and the King IV Report on Corporate Governance 2016 take precedence in organisational acquiescence. These transformed South African workplaces impact directly on the type of graduate required for the workplace. However, the 4IR workplace requires preparation and digital upskilling of graduates at South African HEls to become employable. These skill sets need to meet the needs of a digital economy which prepares graduates for both a South African and a global workspace (Bremner \& Laing, 2019). According to Bremner and Laing (2019), universities need to be mindful that they fully address the changing skills requirements of future employers (p. 2).

These are all facets pertaining to the complexities for South African graduates to become employable. The GIG economy is a key part of contemporary workspaces. The GIG economy is defined as contract or part time work but contextualised slightly different (Brinkley, 2016). It is derived from the musical gig, where individuals choose a GIG lifestyle to have control of their hours and the number of jobs they work while attaining a greater skills set. While it may allow flexibility for individuals to attend to matters such as studies or family responsibilities, it is detrimental in a number of ways. Currently there is contention in the regulation of these jobs, specifically in the risk of hours being limited without notice or terminating the employment completely. There are no formalised benefits with the GIG employment. The GIG economy has been critiqued as it relates to its potential for accelerating 'fragmentation': breaking down once-whole jobs into discrete task elements, each of which is then auctioned to the lowest bidder (Healy, Nicholson, \& Pekarek, 2017, p. 7). In South Africa, it is forecasted that the GIG economy will be positive in the alleviation of some of the high unemployment. While this may hold true, the global critique of it being unregulated makes it increasingly volatile in a South African labour market.

\section{COVID-19 impact on employability objectives}

The impact of the global pandemic has been encumbering in a number of ways. Public HE students suffered gravely during the hard lockdown when they had to evacuate residences and return to their homes. They grappled without resources and data connectivity, another resultant circumstance from the structural inequalities of the historical apartheid legislation. Students were negatively impacted by their lack of knowledge of technology and online platforms, while they attempted to navigate through the semester of studies and assessments. However, these challenges provide positive outcomes for future graduate attributes. Once they were able to return to university, they were exposed to an international way of things, which were consistent with 4IR workplaces, to an extent. By default, during the pandemic, they had to self-teach by the use of electronic platforms in order to

Ramnund-Mansingh, A., \& Reddy, N. (2021). South African specific complexities in aligning graduate attributes to employability. Journal of Teaching and Learning for Graduate Employability, 12(2), 206-221. 
communicate, attend lectures and complete assessments. Fortuitously, a global pandemic created an opportunity for thousands of students to develop technological savviness. The impact is far reaching as it provides a basic framework for online work opportunities globally and within the country. The transformed online teaching pedagogies within COVID-19 has paved the way for employability post-graduation.

\section{A clinical intervention}

The following table provides a clinical intervention by outlining the various influencing factors and the skills sets required for graduates to be employable in a South African perspective. The intervention is designed by $\operatorname{Dr}$ Ramnund-Mansingh as her specialist discipline area is clinical sociology.

Table 1: Clinical Intervention Model Aligning Graduate Attributes to Employability

\begin{tabular}{|c|c|c|c|}
\hline Employability skills set & $\begin{array}{l}\text { South African specific } \\
\text { Risks }\end{array}$ & Response & Clinical Intervention \\
\hline $\begin{array}{l}\text { Varied skills for } \\
\text { employability: } \\
\text { - } \quad \text { Balanced world view } \\
\text { (inclusive system } \\
\text { science model) } \\
\text { - } \quad \text { Working with a } \\
\text { multitude of people } \\
\text { across generations } \\
\text { - } \quad \text { Communication } \\
\text { - }\end{array}$ & $\begin{array}{l}\text { A colonised HE } \\
\text { curriculum }\end{array}$ & $\begin{array}{l}\text { Personal skills associated } \\
\text { with 4IR competencies } \\
\text { Professional skills } \\
\text { associated with 4IR } \\
\text { competencies } \\
\text { Technical proficiencies } \\
\text { associated with 4IR }\end{array}$ & $\begin{array}{l}\text { - Enhanced curriculum } \\
\text { design to incorporate } \\
\text { application type } \\
\text { assessments to } \\
\text { evaluate personal } \\
\text { traits } \\
\text { - Curriculum design to } \\
\text { integrate simulated } \\
\text { workplace scenarios } \\
\text { and team based } \\
\text { interactions to } \\
\text { evaluate professional } \\
\text { skills set } \\
\text { - Technological mind- } \\
\text { sets and proficiency } \\
\text { evaluated by } \\
\text { specialised modules }\end{array}$ \\
\hline
\end{tabular}

Ramnund-Mansingh, A., \& Reddy, N. (2021). South African specific complexities in aligning graduate attributes to employability. Journal of Teaching and Learning for Graduate Employability, 12(2), 206-221. 


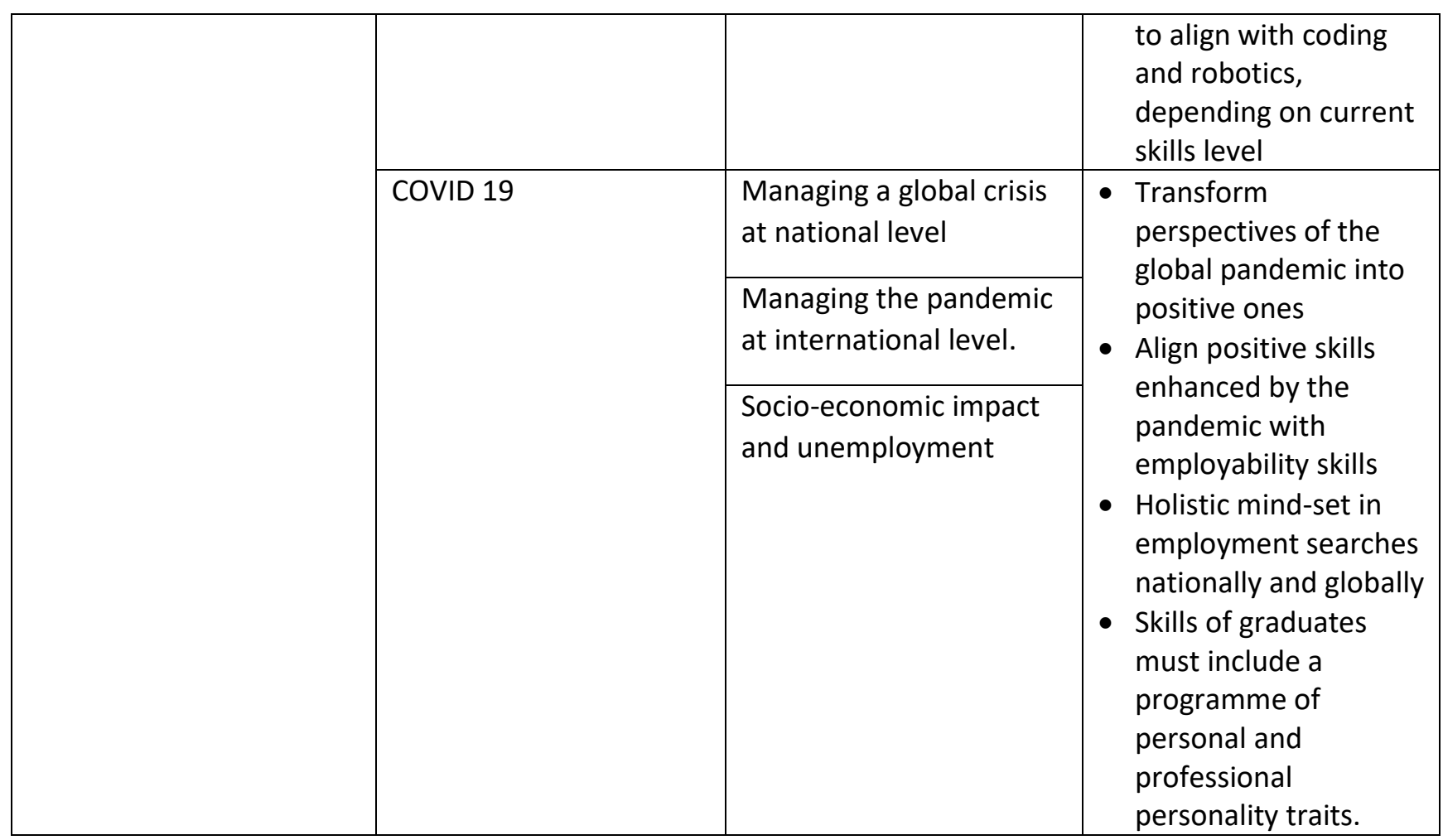

Table 1 provides a detailed clinical sociological intervention and explicates the factors influencing the employability from graduate attributes, emanating from South African associated risks which include the decolonisation of the HE curriculum, 4IR specific skills and responses to COVID-19. The intervention provides responses and clinical interventions to generic employability skills by taking cognisance of the South African specific risks.

The above clinical model was transferred into the lotus flower analogy (Figure 1), which symbolises a lotus flower that emerges from murky waters representing varying challenges that students encounter. This includes lack of technological understanding, access to resources and poor data connectivity infrastructure. In the beginning the bud lies below the dense waters of darkness and uncertainty which represents the South African specific risks. The flower gradually gravitates towards the warmth of the sun through acknowledgement of confronted risks. The evolution of the lotus flower is the ascent through the murky waters, a metaphor for the clinical intervention derived through knowledge and research, as it continues reaching out to the sun regardless of the environment. The final stage is when the lotus bud blossoms into a beautiful flower which is recognised as the attributes of an employable graduate. 


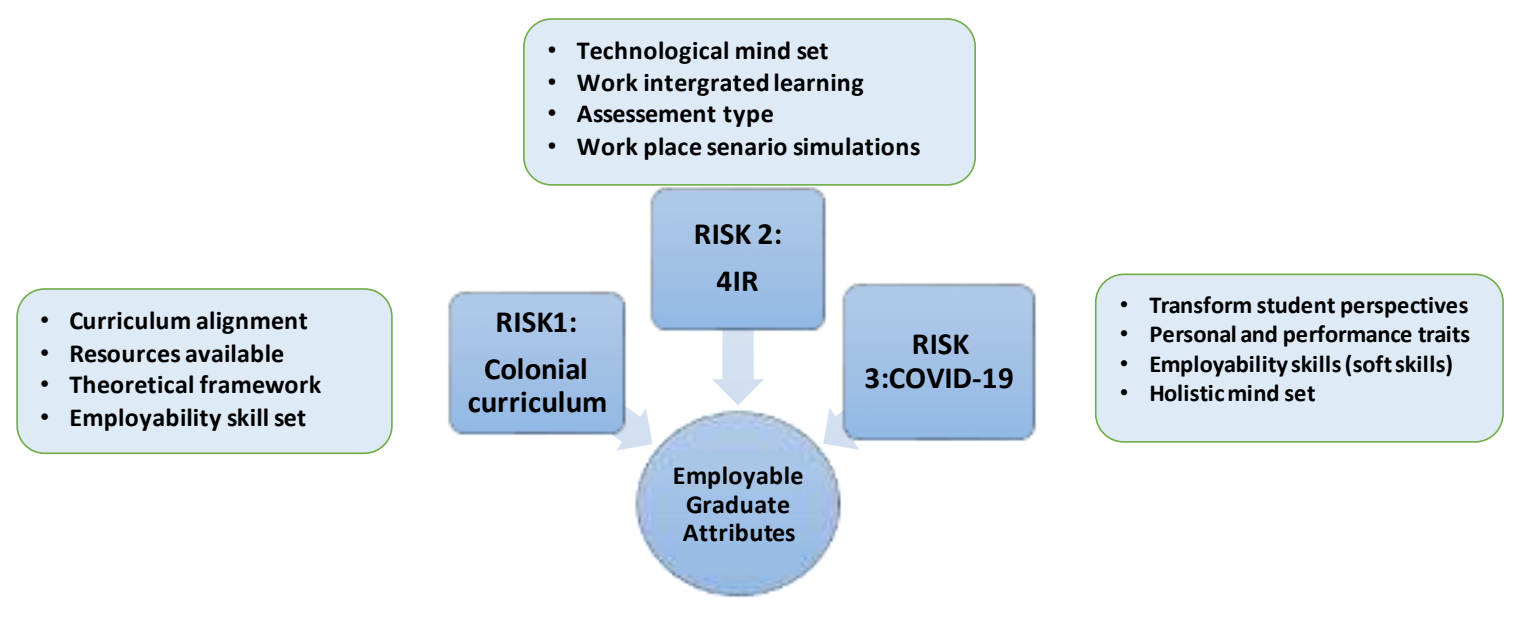

Figure 1: The Lotus Flower Analogy to Align the Risks with Employable Graduate Attributes

\section{Conclusion}

While the world grinds to a screeching halt with the global COVID-19 pandemic, South Africans view it as a calamity on their list of dilemmas. Graduate employability is critical in a country grappling with the structural inequalities that political democracy should have long rectified. HE is the link between graduates and employment in a country where unemployment was steadfast at almost $30 \%$ before COVID-19. While the world responds to the 4IR trends, South African HE had to decolonise a somewhat fallacious colonial curriculum. The need for higher education to respond is urgent as the power of 4IR technologies for either positive social impacts or devastating environmental damage is upon us, as is the potential for irreversible loss of control over networks of powerful Al agents with increasing autonomy within financial sectors and within urban infrastructure (Penprase, 2018, p. 217). The double edged sword comes into play when there is such significant competition for fewer jobs and this is when a 4IR curriculum is of importance. The need for HEls to provide work integrated learning is vital in the development of graduates. This provides students with the opportunity to apply their knowledge and skills within a professional setting, whilst under supervision (Hall, Pascoe \& Charity, 2017).

This paper discussed the literature of the progression of graduate attributes and what is required for employability, while creating adequate knowledge of the multi-generational workplace. Responding to this is a clinical model with designed clinical interventions in order to respond to the three key areas of decolonisation of curriculum, 4IR skills and COVID-19. It is evident that these core aspects need to be addressed in entirety to equip students with the necessary skills to enter a job market nationally or globally. Additionally, there is an opportunity to join the GIG world economy which is conjectured to impact positively for the high unemployment in the country. While the gig economy may allow some workers to smooth their volatile incomes, it is unlikely (on its own) to help large numbers of jobseekers who face other significant barriers to entering employment (Healy et al., 2017, p. 9). As with COVID-19, the transition in private HE systems was seamless, so too is private higher education taking the lead in equipping their students with employability skills. Currently programmes are being piloted, while short courses to enhance employability skills sets are being designed and executed.

A key limitation of the study included only research that have been published in scientific and verified sources. There may be other innovative models that have either not been captured, still in experimental phase or have never considered the impact of a pandemic. Due to COVID-19 and locked down regulations, researchers could not conduct a case based study with research methods and tools to conduct primary data collection. Therefore, the clinical intervention model aligning graduate attributes to employability can be applied in a HE facility as a case study for future areas of

Ramnund-Mansingh, A., \& Reddy, N. (2021). South African specific complexities in aligning graduate attributes to employability. Journal of Teaching and Learning for Graduate Employability, 12(2), 206-221. 
research. The study can further investigate a student's journey through the HEI and provide alignment to the relevant organisations globally.

\section{Reference List}

Abraham, K.G., Haltiwanger, J., Sandusky, K. and Spletzer, J., (2019). The rise of the gig economy: fact or fiction? In AEA Papers and Proceedings, 109, 357-61.

Ahmadi, M., \& Helms, M.M. (1997). Small firms, big opportunities: the potential of careers for business graduates in SMEs. Education and Training, 39(2), 52-57.

Ali, W. (2020). Online and remote learning in higher education institutes: A necessity in light of COVID-19 Pandemic. Higher Education Studies, 10(3), 16-25.

Bascha, Z. (2011, September 19). The open source generation. Retrieved from http://opensource.com/business/11/9/z-open-source-generation

Bennett, D., Knight, E., Divan, A., Kuchel, L., Horn, J., van Reyk, D., \& Burke da Silva, K. (2017). How do research-intensive universities portray employability strategies? A review of their websites. Australian Journal of Career Development, 26(2), 52-61.

Bitzer, E. (2009). Higher Education in South Africa. SUN Media. Stellenbosch.

Born, N., \& Drori, E. (2015, March). What factors will transform the contemporary work environment and characterize the future of work? Retrieved from https://ecommons.cornell.edu/bitstream/handle/1813/74542/What Factors Will Transform the Con temporary Work Environment and Characterize the Future of Work.pdf?sequence $=1$ \&isAllowed=y

Bremner, P. A., \& Laing, A. (2019). The disrupted workplace: Are the digital and group skills needs of employers being addressed by universities? Journal of Learning Development in Higher Education, (16). https://doi.org/10.47408/jldhe.v0i16.535

Bridgstock, R. (2009). The graduate attributes we've overlooked: Enhancing graduate employability through career management skills. Higher Education Research \& Development, 28(1), 31-44.

Brinkley, I. (2016). In search of the gig economy. The Work Foundation Lancaster University. Retrieved from https://www.lancaster.ac.uk/media/lancaster-university/contentassets/documents/lums/work-foundation/reports/407 In-search-of-the-gigeconomy June2016 Access(1).pdf

Buckenmeyer, J.A. (2010). Beyond computers in the classroom: Factors related to technology adoption to enhance teaching and learning. Contemporary Issues in Education Research, (CIER), 3(4), 27-36.

Constanza, D. P., Badger, J. M., Fraser, R. L., Severt, J. B., \& Gade, P. A. (2012). Generational differences in the work-related attitudes: A meta-analysis. Journal of Business Psychology, 27, 375-394.

Dacre Pool, L., and Sewell, P. (2007). The Key to Employability: Developing a Practical Model of Graduate Employability. Education and Training, 49(4), 277-289.

De Stefano, V. (2015). The rise of the just-in-time workforce: On-demand work, crowd work, and labor protection in the gig-economy. Comparative Labour Law and Policy Journal, 37(3), 471-504.

Donovan, S.A., Bradley, D.H., \& Shimabukuru, J.O. (2016). What does the gig economy mean for workers? (CRS Report R44365). Washington, DC: Congressional Research Service.

Gaidhani, S., Arora, L., and Sharma, B. K. (2019). Understanding the attitude of generation Z towards workplace. International Journal of Management, Technology and Engineering, 9(1), 2804-2812.

Generational White Paper. (2011). Generation Z and the Career Strategist. Retrieved from http://www.workcomms.com/graduates/whitepapers/Generation-Z/

Gill, R. (2018). Building employability skills for higher education students: An Australian example. Journal of Teaching and Learning for Graduate Employability, 9(1), 84-92.

Goldie, J. G. S. (2016). Connectivism: A knowledge learning theory for the digital age? Medical Teacher, 38(10), 1064-1069.

Green, D.D. (2018). Fuelling the gig economy: A case study evaluation of Upwork.com. Management and Economic Research Journal, 4, 104-112.

Gupta, S and Garg, S. (2020). COVID-19 and higher education: Some issues. World University News - A Weekly Journal of Higher Education Published by the Association of Indian Universities, 58 (23), 3-8. Retrieved from https://www.aiu.ac.in/documents/AIU Publications/University News/UNIVERSITY\%20NEWS\%20VOL58,\%20NO-23,\%20JUNE\%2008-14,\%202020.pdf

Habib, A., Morrow, S., \& Bentley, K. (2008). Academic freedom, institutional autonomy and the corporatised university in contemporary South Africa. Social dynamics, 34(2), 140-155.

Ramnund-Mansingh, A., \& Reddy, N. (2021). South African specific complexities in aligning graduate attributes to employability. Journal of Teaching and Learning for Graduate Employability, 12(2), 206-221. 
Hall, M., Pascoe, D., \& Charity, M. (2017). The Impact of Work-Integrated Learning Experiences on Attaining Graduate Attributes for Exercise and Sports Science Students. Asia-Pacific Journal of Cooperative Education, 18(2), 101-113.

Healy, J., Nicholson, D., \& Pekarek, A. (2017). Should we take the gig economy seriously? Labour and Industry: A Journal of the Social and Economic Relations of Work, 27(3), 232-248.

Heleta, S. (2016). Decolonisation of higher education: Dismantling epistemic violence and Eurocentrism in South Africa. Transformation in Higher Education, 1(1), 1-8.

Higher Education Act 101 of 1997 (amended 2010). Retrieved from www.che.ac.za

Hinchliffe, G. W., \& A. Jolly. (2011). Graduate Identity and Employability. British Educational Research Journal, 37(4), 563- 584.

Jackson, D. (2012). Testing a model of undergraduate competence in employability skills and its implications for stakeholders. Journal of Education and Work, 27(2), 1-23.

Jansen, J.D. (1998). But our natives are different! Race, knowledge and power in the academy. Social Dynamics, 24(2), 106-116.

Jones, L. M. (2017). Strategies for retaining a multigenerational workforce (Doctoral dissertation). Walden University.

Lau, A., \& Pang, M. (1995). Undergraduates' career perceptions and first job needs in Hong Kong. International Journal of Career Management, 7(3), 14-24.

Lewis, K. (2020). Technology in the workplace: Redefining skills for the 21st Century. The Midwest Quarterly, 61(3), 348-356. Retrieved from https://link.gale.com/apps/doc/A628285354/AONE?u=anon 56b99d0\&sid=googleScholar\&xid=3a790f $\underline{60}$

Lewis, L.F., \& Wescott, H.D. (2017). Multi-generational workforce: Four generations united in lean. Journal of Business Studies Quarterly, 8(3).

Li, H., \& Sun, Z. (2019). Study on the definition of college students' employability. In ITM Web of Conferences (Vol. 25, p. 04001). EDP Sciences.

Lindeque, B. (2020, February 14). South African schools to get coding and robotics from grade $r$ ! Retrieved From https://www.goodthingsguy.com/business/south-africa-schools-codingrobotics/\#: :text=Johannesburg\%2C\%20South\%20Africa\%20(14\%20February,improve\%20education\% 20in\%20the\%20country.

Long, E., \& Fynn, A. (2018). Postgraduate student experiences of workplace learning for a professional psychology qualification in the South African context. Industry and Higher Education, 32(5), 341350. https://doi.org/10.1177/0950422218774701

Macupe, B. (2021, July 11). School dropout rate at its highest. City Press. Retrieved from https://www.news24.com/citypress/news/school-dropout-rate-at-its-highest-20210711

Maluleke, R. (2019). Education Series Volume V: Higher Education and Skills in South Africa, 2017. Statistics South Africa: Pretoria.

McCabe, G. (2010). Graduate attributes and employability: Helping universities and students prepare for the changing landscape. Centre for Teaching, Learning and Assessment. The University of Edinburgh. Retrieved from http://www.ed.ac.uk/files/atoms/files/ga-helping uni and students prepare march2010.pdf

Mendy, J., \& Madiope, M. (2020). Curriculum transformation: A case in South Africa. Perspectives in Education. 38(2), 1-19.

Mohd Abas, M.K., Yahaya, R.A., \& Din, M.S.F. (2019). Digital literacy and its relationship with employee performance in the 4IR. Journal of International Business, Economics and Entrepreneurship (JIBE), 4(2), 29-37.

Mohee, R., \& Putty-Rogbeer, K. (2020). Toolkit for Key Employability Indicators for National Qualification Agencies. Commonwealth of learning. Retrieved from http://oasis.col.org/bitstream/handle/11599/3599/2020 Mohee_PuttyRogbeer Employability Toolkit.pdf?sequence=1\&isAllowed $=y$

Morrison, A. (2014). A class act? Lecturers' views on undergraduates' employability. British Journal of Sociology of Education, 35(4), 487-505.

Oke, A., \& Fernandes, F.A.P. (2020). Innovations in teaching and learning: Exploring the Perceptions of the education sector on the 4th Industrial Revolution (4IR). Journal of Open Innovation: Technology, Market, and Complexity, 6(2).

Onyeike, V.C., \& Onyeagbako, S.O. (2014). Enhancing employability through university education: The role of national university commission (NUC). Global Journal of Educational Research, 13(2), 109-115.

Ramnund-Mansingh, A., \& Reddy, N. (2021). South African specific complexities in aligning graduate attributes to employability. Journal of Teaching and Learning for Graduate Employability, 12(2), 206-221. 
Oraison, H.M., Konjarski, L., \& Howe, S.T. (2019). Does university prepare students for employment? Alignment between graduate attributes, accreditation requirements and industry employability criteria. Journal of Teaching and Learning for Graduate Employability, 10(1), 173-194.

Ozaydin, S. (2019). Organisational culture as a tool for managing a multi-generational workforce in project management. Research Journal of Business and Management, 6(3), 185-203.

Penprase, B.E. (2018). The Fourth Industrial Revolution and higher education. In N. Gleason (Ed) Higher Education in the Era of the Fourth Industrial Revolution (pp. 207-229). Palgrave Macmillan, Singapore.

Ramlachan, P., Ramnund-Mansingh, A., \& Naidoo, K. (In Press). The impact of globalisation on governance of local authorities: A 10-year comparative analysis of eThekwini Municipality. Journal of Public Administration, 56(2), 250-264.

Ramnund, A. (2019). Exploring the link between institutional culture and the career advancement of female academics in higher education: a case study of the University of KwaZulu-Natal, South Africa. (Doctoral Research). University of KwaZulu Natal Durban.

Römgens, I., Scoupe, R., \& Beausaert, S. (2020). Unraveling the concept of employability, bringing together research on employability in higher education and the workplace. Studies in Higher Education, 45(12), 2588-2603.

Ruge, G., Tokede, O., \& Tivendale, L. (2019). Implementing constructive alignment in higher education-crossinstitutional perspectives from Australia. Higher Education Research and Development, 38(4), 833-848.

Sahu, P. (2020). Closure of universities due to Coronavirus Disease 2019 (COVID-19): impact on education and mental health of students and academic staff. Cureus, $12(4)$.

Schawbel, D. (2014). Gen Z employees: The 5 attributes you need to know. Retrieved from http://www.entrepreneur.com/article/236560

Scott, C.A., McLean, A. \& Golding, C. (2019). How peer mentoring fosters graduate attributes. Journal of Peer Learning, 12, 29-44.

Seedat -Khan, M., \& Ramnund-Mansingh, A. (2021). The sociology of a Covid-19 virtual university. ISA Pedagogy Series, 1(1), 60-81. ISA.e-Forum ( )

Smith, M., Bell, K., Bennett, D., \& McAlpine, A. (2018). Employability in a global context: Evolving policy and practice in employability, work integrated learning, and career development learning. Graduate Careers Australia. doi: 10.6084/m9.figshare.6372506.

Statistics South Africa. (2020, December). General Household Survey 2019. Retrieved from http://www.statssa.gov.za/publications/P0318/P03182019.pdf

Stewart, D.W., \& Kamins, M.A. (1994). Secondary Research-information sources and methods. California: Sage Publications.

Wickramasinghe, V., \& Perera, L. (2010). Graduates', university lecturers' and employers' perceptions towards employability skills. Education and Training, 52(3), 226-244.

Wimalasiri, H. S. (2015). Employer's perception on employability skills and attitudes of new graduates: Qualitative insights from the employers in Sri Lanka. Asian Journal of Multidisciplinary Studies, 3(11), 112-120.

Wong, B., Chiu, Y. L. T., Copsey-Blake, M., \& Nikolopoulou, M. (2021). A mapping of graduate attributes: what can we expect from UK university students? Higher Education Research and Development, 1-16.

Yorke, M., \& Knight, P. (2006). Embedding employability into the curriculum. Vol. 3. York: Higher Education Academy

Zakaria, N.S., Yussof, K.Y.S.K.M., Ibrahim, D. and Tibok, R.P. (2020). Career after graduation: future graduates' perceptions of job attributes in small and medium enterprises (SMEs) and multi-national corporations (MNCs). e-Bangi, 17(6), 252-264. 